\title{
Vegetative Anatomy of the New Caledonian Endemic Amborella trichopoda: Relationships with the Illiciales and Implications for Vessel Origin ${ }^{1}$
}

\author{
Sherwin Carlquist and Edward L. Schneider ${ }^{2}$
}

\begin{abstract}
Light microscopy was used to study leaf hypodermis, vein sclerenchyma, stomatal subsidiary cell types, and stem and root xylem in liquid-preserved material of Amborella trichopoda; oblique borders on tracheid pits, scalariform end walls on tracheids, and porosities in end-wall pit membranes were studied with scanning electron microscopy. Amborella shares stomatal configurations, nodal type (in part), ray types, and porose pit membranes in tracheary elements with Illiciales s.l., but differs from that order in lacking oil cells, vessels, and grouped axial parenchyma cells. These data are consistent with a basal position in angiosperms for Amborella, and for a close relationship with, but not inclusion in, Illiciales; inclusion in a monofamilial order is conceivable. Both loss of pit membranes or pit membrane portions on end walls and increase in cell diameter are requisites for origin of vessels. Sarcandra and Illiciaceae show these early stages in origin of vessels; Amborella shows development of porosities in pit membranes. Vessel presence or absence may not be strictly bipolar, because some primitive vessel elements exhibit at least some tracheidlike characteristics and are thus transitional, and because changes in at least two characters define vessel origin.
\end{abstract}

The single species of Amborellaceae (Amborella trichopoda Baill., New Caledonia) is claimed to be the sister group to the remainder of angiosperms according to recent studies (Mathews and Donoghue 1999, Parkinson et al. 1999, Qiu et al. 1999, Soltis et al. 1999). These studies each analyzed more than a single gene site, and this expanded data base as well as the similarity of the cladistic results yielded by these studies have commanded attention by phylogenists. Branching from the cladogram just above Amborella are Nymphaeales (excluding Nelumbonaceae), and then an expanded Illiciales (Illiciaceae, Schisandraceae, Austrobaileyaceae, Trimeniaceae). This treatment was foreshadowed by the results of the Angiosperm Phylogeny

\footnotetext{
${ }^{1}$ Manuscript accepted 17 November 2000.

2 Santa Barbara Botanic Garden, 1212 Mission Canyon Road, Santa Barbara, California 93105.
}

Pacific Science (2001), vol. 55, no. 3:305-312 (C) 2001 by University of Hawai'i Press All rights reserved
Group (1998), who placed a similar roster of families in an unnamed grouping cited first (and thus basal) in their ordering of angiosperms. The phylogenetic significance of anatomical features of Amborella potentially becomes very considerable.

In terms of vegetative anatomy, Amborella had already attracted attention because of the vesselless nature of its wood (Tieghem 1900, Bailey and Swamy 1948, Bailey 1957). Bailey regarded vessellessness as a primitive feature in woody dicotyledons, whereas recent cladists, beginning with Young (1981), regarded vessellessness as a derived condition in woody dicotyledons (for a discussion, see Baas and Wheeler 1996). The more recent cladistic work, cited above, by placing Amborella in a basal position in angiosperms, reopens the possibility that vessellessness is a primitive feature. If this possibility is valid, the nature of tracheids in Amborella becomes worthy of consideration.

By means of scanning electron microscopy (SEM), we are attempting to show whether tracheids of Amborella are transitional to vessels in any respect, and, by inference, whether 
vessels of Illiciales are essentially relatively little-modified versions of tracheids, as hypothesized by Bailey (1944) and Carlquist (1988). If vessel origin is a matter of degrees of intermediacy and change in character state in several characteristics, one can call into question the bipolarity of the coding of vessel presence in cladistic work.

Our materials differ from those available to earlier authors. Bailey and Swamy (1948) had only dried materials and therefore were unable to illustrate and identify some histological features completely. Bailey (1957) had wood of a relatively large stem, but was unable to present SEM data. We were able to study liquid-preserved material of roots, stems, and leaves of Amborella. These materials permit us to answer whether Amborella has oil or mucilage cells, the presence of which was denied by Bailey and Swamy (1948), although claimed by Perkins (1898), and to offer reports on other histological features hitherto undescribed. A useful summary of vegetative anatomy of Amborella was offered by Metcalfe (1987). If Amborella is the sister group to the remainder of dicotyledons, the character state of each feature in this plant takes on greater potential significance and aids in finding the best taxonomic and phylogenetic treatment for the genus.

\section{MATERIALS AND METHODS}

Data on wood are derived from a dried wood sample $7 \mathrm{~cm}$ in diameter (voucher: Carlquist 750 , RSA), collected on the slopes of the Plateau de Dogny, New Caledonia. Neither our samples nor those of other workers included bark, and thus there is no good data on the nature of secondary phloem in $A m$ borella. Fresh material of roots, stems, and leaves was furnished by Brett Hall from plants cultivated in the Arboretum of the University of California at Santa Cruz. These materials were fixed in $50 \%$ aqueous ethanol. The dried wood sample was sectioned on a sliding microtome. The liquid-preserved material was sectioned in paraffin after softening in ethylene diamine (Carlquist 1982a). Some sections were observed with a SEM (Bausch \& Lomb Nanolab). Other sections were stained with a safranin-fast green combination corresponding to Northen's modification of Foster's tannic acid-ferric chloride method (Johansen 1940). Portions of leaves were cleared in lactic acid and observed with light microscopy. The original data presented below are restricted to features not previously observed or for which conflicting data have been published elsewhere.

\section{RESULTS}

\section{Leaf Anatomy}

Leaves of Amborella are variously lobed and without well-demarcated teeth (Figure 1). This is reflected in the venation, in which easily definable hydathodes are not evident. Freely terminating vein endings are common at the margin; there is no marginal vein. Cleared leaf portions and paradermal sections (Figure 2) showed that stomata are densely scattered over the abaxial leaf surface; stomata overlie veins as well as areoles.

The variability of stomatal subsidiary cell arrangement is illustrated in Figure 2. Variations on a paracytic type are common, but other types can be found at lower frequencies.

Leaf transections and clearings show that adaxial epidermal cells are larger than the abaxial ones (Figure 3). We observed groups of cells with thick gelatinous wall portions (Figure 3, above right); the walls facing the center of such cell groups are thickest, whereas distal walls are of normal thickness. We are uncertain how to define these cell groups. Although they could be a definable cell type for the species, we are inclined to record them as an abnormality unless further studies reveal them to be characteristic of the species. We did not observe any cells that bear any of the characteristics of mucilage or oil cells. Although the subepidermal layer of cells on the adaxial side of the leaf is not clearly definable as a hypodermis on the basis of cell size, that layer does have fewer chloroplasts per cell than do cells of other mesophyll layers of the leaf (Figures 3,4). Intercellular spaces are small (Figures 3, 4).

Both smaller veins (Figure 4) and larger veins, such as the midvein, are sheathed with 

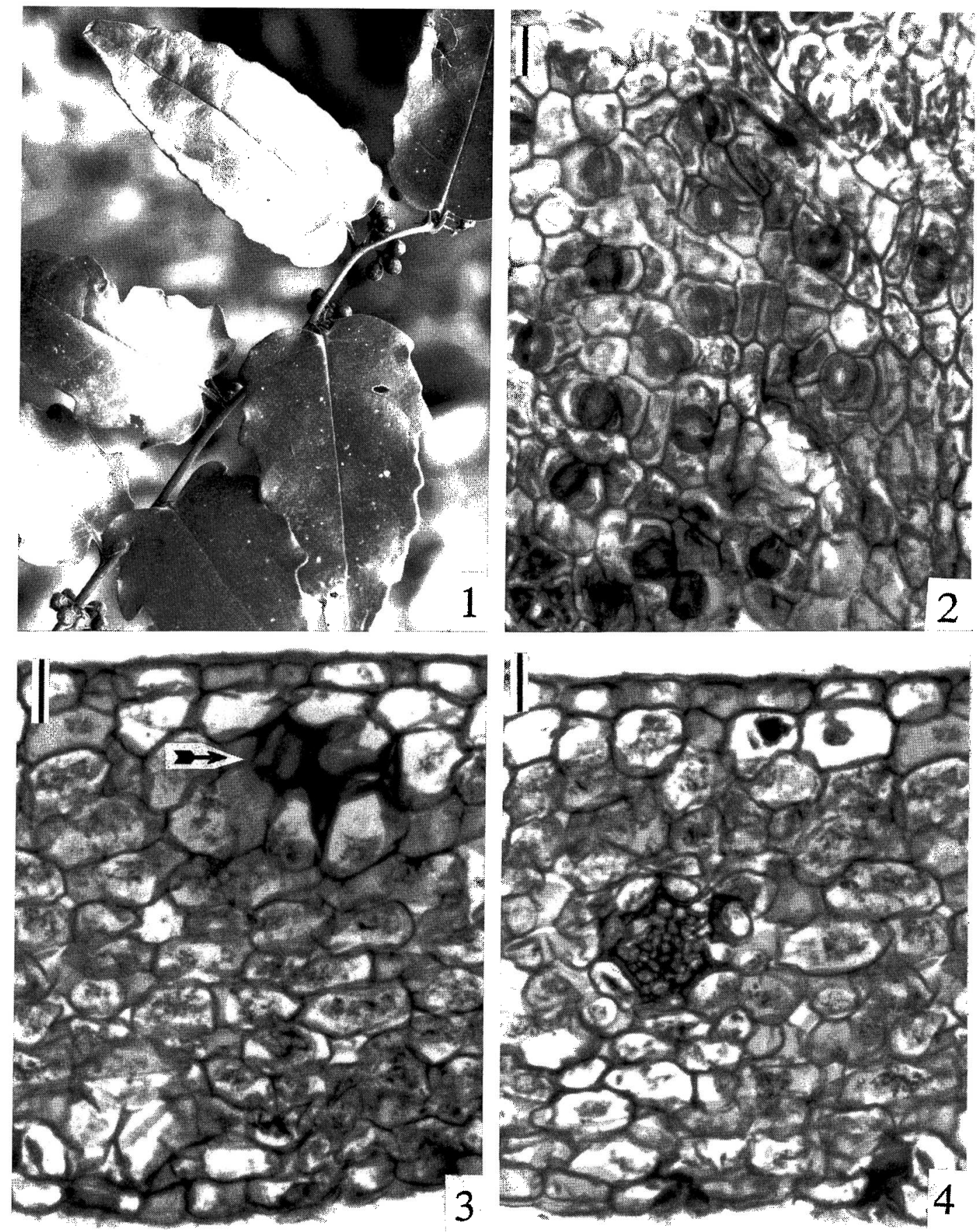

Figures 1-4. Amborella tricbopoda. 1, Habit of branch bearing fruits; 2, paradermal section, showing stomata with varied subsidiary cells arrangements. 3-4. Transection of lamina of leaf. 3, Portion showing paucity of chloroplasts in hypodermis; and a group of cells with thick wall portions (arrow); 4, portion showing a minor vein sheathed by sclereids with hippocrepiform thickenings. Length of branch in Figure 1, 0.5 m; bars in Figures 2-4, $30 \mu \mathrm{m}$. 
sclereids said to have hippocrepiform (horseshoe-shaped) lignified thickenings. These thickenings occur on five of the six walls of each sclereid and are absent on the wall most distal from the vein. Such sclereids have been reported in the stems of Amborella also.

\section{Secondary Xylem}

Wood of a mature stem shows variations in radial diameter of tracheids: a few layers of somewhat narrower than average tracheids are succeeded by a few layers of somewhat wider than average tracheids (Figure 5, arrow) Very weakly defined growth rings are present. The wider "earlywood" tracheids are the ones that bear scalariform pitting (e.g., Figures 10,13), on radial end walls, although Bailey (1957) found that scalariform pitting was distributed randomly within the wood. We also found numerous tracheids in which radial end walls bear pits intermediate between circular and typical scalariform shapes (Figure 8).

The mature wood pattern of Amborella features some multiseriate rays up to five cells in width (Figure 6, near center), but in our material uniseriate and biseriate rays predominate (Figure 6). Upright to square cells compose rays, for the most part (Figure 7), but at least a few files of procumbent cells are present in radial sections of wider rays. Ray cells contain droplets or massive yellowish to brownish deposits (dark cellular contents in Figures 5-7), but no ethereal oil or mucilage cells are present. Ray cells have lignified secondary walls. In radial sections, we noted that many of the pits in ray cells are bordered, as illustrated by Bailey (1957).

Axial parenchyma is diffuse, as stated by Bailey (1957), and is easily located in our material (Figure 7, arrows), but is not as abundant as in most dicotyledonous woods with diffuse axial parenchyma. Strands of axial parenchyma are composed of about five cells that are notably elongate axially. Axial parenchyma contains the droplets of dark-staining compounds cited above for rays.

Figures 8-14 depict scalariform end walls of tracheary elements. Although we have shown two of these without pit membranes (Figures 8,10 ), we believe that these repre- sent artifacts of processing and handling, and that pit membranes are characteristically present. Presence of pit membranes is shown clearly in the section of a scalariform end wall (Figure 9). In Figure 8, pit apertures run obliquely to the pit borders, a feature we observed commonly in Amborella wood.

Both in stems (Figures 11-13) and in roots (Figure 14), porose pit membranes were observed. Exposure to the SEM electron beam caused membrane displacement and damage that we could watch. Hence, some of the tears visible (e.g., Figure 14, right) may represent artifacts caused by this; minimizing duration of exposure to the beam at higher magnifications proved the most successful remedy. The pit membranes of scalariform pits in Amborella tracheids that were observed included the following variations: (1) membranes with porosities that are circular and relatively uniform in size (Figure 11); (2) membranes appearing like a finely porose sheet, with a few larger holes (Figure 12); (3) membranes with a wide range of hole sizes, some holes separated by threadlike membrane remnants (Figure 13); and (4) membranes with circular to angular holes, ranging downward in diameter below the resolving power of our SEM (Figure 14). We believe that these porosities do not represent artifacts, but additional observations, especially those utilizing other methods, are desirable.

We observed secondary wood of relatively young roots (two years' accumulation of secondary xylem) and found it to be like that of stems in all essentials, except that tracheids are uniform in diameter. The roots studied were diarch.

\section{DISCUSSION AND CONCLUSIONS}

\section{Relationships and Pbylogeny}

The placement of Amborella as basal in angiosperms by recent workers suggests that vessellessness must be regarded as basal in dicotyledons. This possibility tends to be reinforced by the apparent absence of vessels in some Nymphaeales and the presence of vessels with rudimentary development of pores in pit membranes in other genera (Schneider and Carlquist 1995a,b, 1996a,b, 

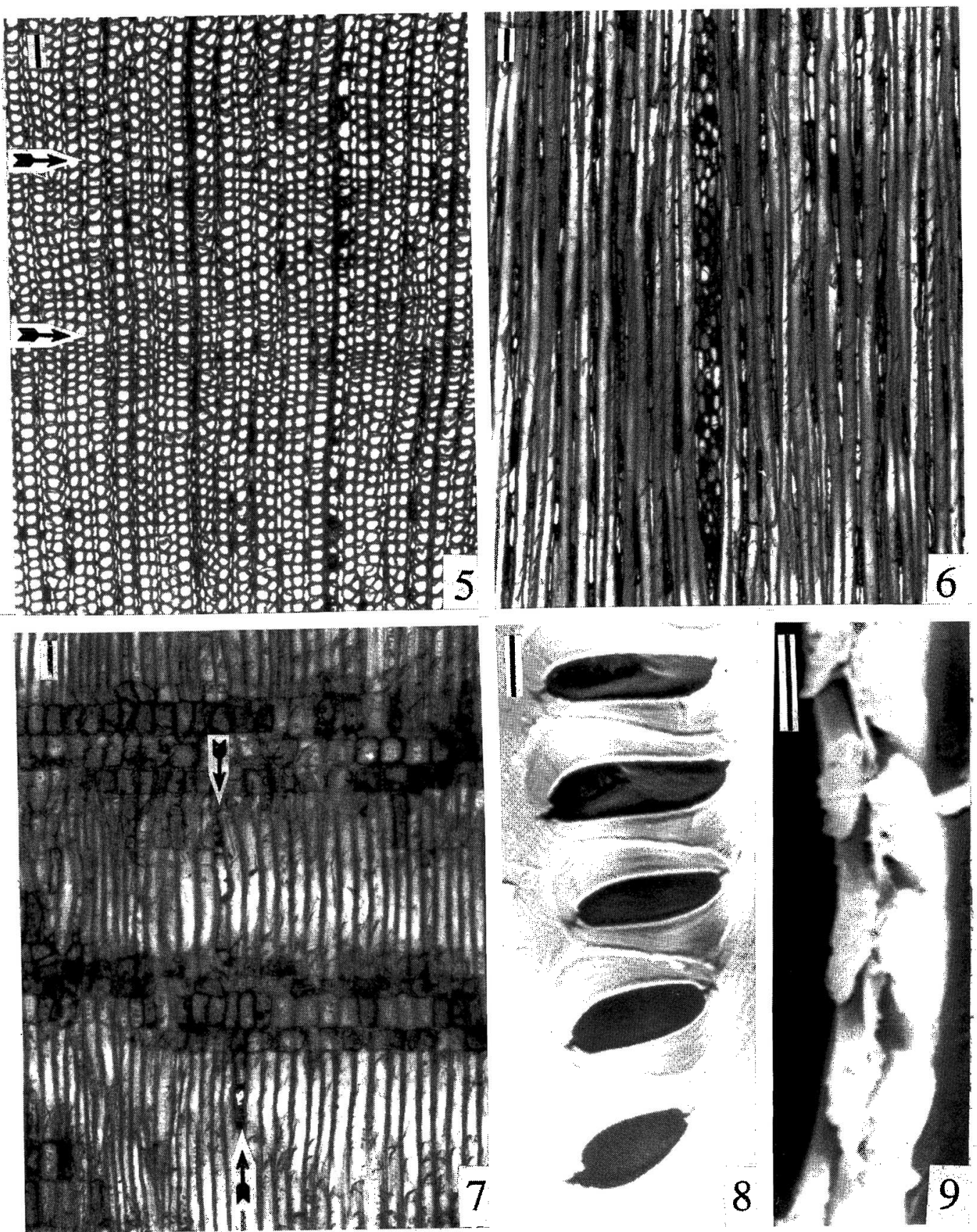

Figures 5-9. Wood of Amborella trichopoda. 5, Transection of mature stem, showing barely discernible growth rings (beginning of earlywood indicated by arrows) and absence of vessels; 6 , tangential section of mature wood; one ray wide and multiseriate, and others uniseriate or biseriate; 7, radial section of mature stem, showing dark-staining deposits in ray cells and (arrows) two strands of axial parenchyma. 8-9. SEM photographs of wood from young root. 8, Face view of pits on end wall (pit membrane absence considered an artifact), showing offset of angle of pit apertures Face view of pits on end wall (pit membrane absence considered an ance of pit membrane in pits. Bars indicate magnifications (Figures 5-7, $60 \mu \mathrm{m}$; Figures $8-9,5 \mu \mathrm{m}$ ). 

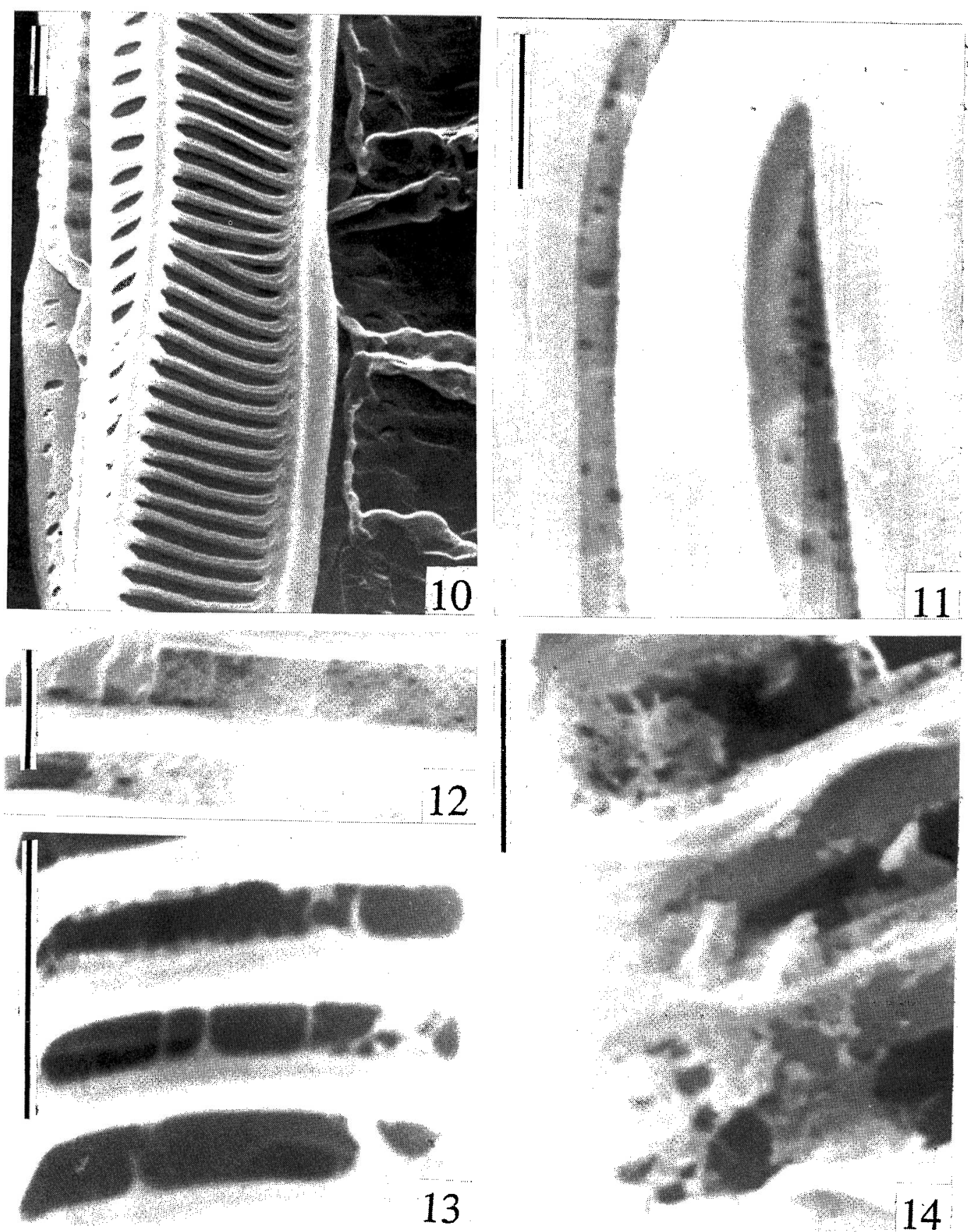

FIgUREs 10-14. SEM photographs of tracheids from macerations of wood of Amborella tricbopoda. 10-13. Wood from mature stem. 10, Scalariform end wall of tracheid (absence of pit membranes considered an artifact), with a second tracheid in back of it (left), and, to right, ray cells; 11, portions of two scalariform pits from end wall, showing circular pores in pit membranes; 12, portions of two scalariform pits from end wall, showing thin meshworklike pit membrane containing a few small circular pores; 13 , pit membrane remnants in scalariform end wall pits; 14, portions of three scalariform pits from tracheid of young root secondary xylem, showing pores in pit membranes (large tears considered to be artifacts). Bar in Figure 10,10 $\mu \mathrm{m}$; bars in Figures 11-14, $5 \mu \mathrm{m}$. 
Schneider et al. 1995). The next most basal group in recent phylogenies, Illiciales s.l., has vessels. Other features that distinguish Amborella from Illiciales s.l. are the presence of mucilage or oil cells in Illiciales and the occurrence of paratracheal axial parenchyma (often abaxial, and scanty in any case) in Illiciales (data from Carlquist 1982b, 1984, $1999,2001)$. By virtue of having no vessels, axial parenchyma in Amborella is by definition apotracheal, but there can be grouped apotracheal cells rather than diffuse ones even in a vesselless dicotyledon (e.g., Winteraceae: Carlquist 1989), and thus the paratracheal axial parenchyma of Illiciales does contrast with the diffuse axial parenchyma of Amborella.

The families of Illiciales s.l. can all be said to have paracytic stomata, with transitions to other types (Carlquist 2001). In this respect, there is a link between Amborella and the Illiciales. Nodes are unilacunar with a single trace in Amborella, a condition found also in Illicium; the remaining Illiciales have unilacunar two-trace nodes (Metcalfe 1987), a condition that probably is morphologically similar to the unilacunar one-trace arrangement.

\section{Vessel Origin and Definition}

The vesselless dicotyledons have small porosities in end walls of tracheids, end walls that often are scalariform. Such porous pit membranes have been illustrated for Bubbia of the Winteraceae (Carlquist 1983) and Tetracentron of the Tetracentraceae or Trochodendraceae (Carlquist 1988). Amborella also has porosities in this size range. The somewhat larger pit membrane holes (Figure 13) may be natural and may represent removal of larger portions of pit membranes by the conductive stream over time. Such porose pit membranes may be found in such Illiciales as Illicium (Carlquist 1992), Schisandraceae (Carlquist 1999), and Austrobaileya (Carlquist 2001).

Stages in reduction of the pit membrane remnants are well illustrated in Illicium (Carlquist 1992) and show how porose membranes likely yielded to clear perforations through more extensive and efficient lysis of the membrane. A second criterion for origin of vessels is differentiation between diameters of vessels and those of the tracheids, as in the roots of Sarcandra (Carlquist 1987) and Illicium (Carlquist 1982b) and the other Illiciales s.l.

On the basis of these criteria, Amborella shows porose pit membranes in end walls (rather than nonporose end walls); no differentiation in element diameter other than that attributable to growth rings is present.

However, stages associated with the origin of vessels, including dimorphic diameter of tracheary elements and change to more porose pit membranes, have been demonstrated in Illicium and Sarcandra (Carlquist 1982b, 1987). Vessel elements in these genera show the transitions between the morphology of tracheids in a vesselless wood and the morphology of tracheids and vessel elements in a primitive wood. Dimorphism in tracheary element diameter and presence of pores in pit membranes of end walls are features of degree rather than "bipolar" characters of presence or absence. Moreover, change in more than one character state is required for vessel origin. Herendeen and Miller (2000) advised against use in cladistical analysis of features that cannot be cast into bipolar form, and thus "vessels absent" versus "vessels present" is an unreliable contrast because it conflates more than one character.

\section{ACKNOWLEDGMENTS}

We express our appreciation for the efforts of Ray Collett, founding director of the University of California, Santa Cruz, Arboretum, who made certain that live material of $\mathrm{Am}$ borella was brought to the United States, and to Brett Hall, who provided material to us from the plants cultivated at that Arboretum. Don Zack (Engineering, University of California at Santa Barbara, retired) has tirelessly helped us obtain the maximal performance possible from our SEM.

\section{Literature Cited}

Angiosperm Phylogeny Group. 1998. An ordinal classification for the families of flowering plants. Ann. Mo. Bot. Gard. 85:531-553.

Baas, P., and E. A. Wheeler. 1996. Parallel- 
ism and reversibility in xylem evolution-a review. IAWA J. 17:351-364.

Bailey, I. W. 1944. The development of vessels in angiosperms in morphological research. Am. J. Bot. 31:421-428.

1957. Additional notes on the vesselless dicotyledon, Amborella trichopoda Baill. J. Arnold Arbor. Harv. Univ. 38:374-378.

Bailey, I. W., and B. G. L. Swamy. 1948. Amborella trichopoda Baill., a new morphological type of vesselless dicotyledon. J. Arnold Arbor. Harv. Univ. 29:245-254.

Carlquist, S. 1982a. The use of ethylene diamine in softening hard plant structures for paraffin sectioning. Stain Technol. 57:311-317.

- 1982b. Wood anatomy of Illicium (Illiciaceae): Phylogenetic, ecological, and functional interpretations. Am. J. Bot. 69:1587-1598.

- . 1983. Wood anatomy of Bubbia (Winteraceae), with comments on origin of vessels in dicotyledons. Am. J. Bot. 70:578-590.

- 1984. Wood anatomy of Trimeniaceae. Plant Syst. Evol. 144:103-118.

- 1987 . Presence of vessels in wood of Sarcandra (Chloranthaceae): Comments on vessel origin in angiosperms. Am. J. Bot. 74:1765-1771.

-. 1988. Comparative wood anatomy. Springer Verlag, Heidelberg.

_ _ 1989. Wood anatomy of Tasmannia; summary of wood anatomy of Winteraceae. Aliso 12:257-275.

—_. 1992. Pit membrane remnants in perforation plates of primitive dicotyledons and their significance. Am. J. Bot. 79:660-672.

- 1999. Wood and bark anatomy of Schisandraceae: Implications for phylogeny, habit, and vessel evolution. Aliso $18: 45-55$.

- 2001. Observations on the vegetative anatomy of Austrobaileya: Habital, organographic, and phylogenetic considerations. Bot. J. Linn. Soc. 135:1-11.

Herendeen, P. S., and R. B. Miller. 2000. Utility of wood anatomic characters in cladistic analysis. IAWA J. 21:247-276.
Johansen, D. A. 1940. Plant microtechnique. McGraw-Hill, New York.

Mathews, S., and M. J. Donoghue. 1999. The root of angiosperm phylogeny inferred from duplicate phytochrome genes. Science (Washington, D.C.) 286:947-950.

Metcalfe, C. R. 1987. Anatomy of the dicotyledons, 2nd ed. Vol. 3. Magnoliales, Illiciales, and Laurales. Oxford University Press, Oxford.

Parkinson, C. L., K. L. Adams, and J. D. Palmer. 1999. Multigene analyses identify the three earliest lineages of extant flowering plants. Curr. Biol. 9:1485-1488.

Perkins, J. R. 1898. Beiträge zur Kenntniss der Monimiaceae. I. Bot. Jahrb. 25:547577.

Qiu, Y.-L., J. Lee, F. Bernasconi-Quadroni, D. E. Soltis, P. S. Soltis, M. Zanis, E. A. Zimmer, Z. Chen, V. Savolainen, and M. W. Chase. 1999. The earliest angiosperms: Evidence from mitochondrial, plastic, and nuclear genomes. Nature (Lond.) 402: 404-407.

Schneider, E. L., and S. Carlquist. 1995a. Vessels in roots of Barclaya rotundifolia (Nymphaeaceae). Am. J. Bot. 82:13431349.

1995b. Vessel origins in Nymphaeaceae: Euryale and Victoria. Bot. J. Linn. Soc. 119:185-193.

_. 1996a. Vessels in Brasenia (Cabombaceae): New perspectives on vessel origin in primary xylem of angiosperms. Am J. Bot. 83:1236-1240.

__. 1996b. Vessel origin in Cabomba. Nord. J. Bot. 16:637-647.

Schneider, E. L., K. Beamer, and A. Kohn. 1995. Vessels in Nymphaeaceae: Nupbar, Nympbaea, and Ondinea. Int. J. Plant Sci. 156:857-862.

Soltis, P. S., D. E. Soltis, and M. W. Chase. 1999. Angiosperm phylogeny inferred from multiple genes as a tool for comparative biology. Nature (Lond.) 402:402-404.

Tieghem, P. van. 1900. Sur les dicotylédones du groupe des homoxylées. J. Bot. 14:259297, 300-361.

Young, D. A. 1981. Are the angiosperms primitively vesselless? Syst. Bot. 6:313330. 